POLSKA AKADEMIA UMIEJĘTNOŚCI

TOM XIII

KULTURA SŁOWIAN. ROCZNIK KOMISJI KULTURY SŁOWIAN PAU

2017

DOI 10.4467/25439561KSR.17.014.7884

\author{
СЕРГЕЙ БОРТНИК
}

Киевская Духовная Академия

\title{
НАСЛЕДИЕ МИТРОПОЛИТА ПЕТРА МОГИЛЫ ЧЕРЕЗ 400 ЛЕТ: МЕЖДУ ГЕОКУЛЬТУРОЙ И БОГОСЛОВИЕМ
}

\author{
LEGACY OF THE ARCHBISHOP PETER MOGILA \\ AFTER 400 YEARS. CULTURE AND THEOLOGY
}

\begin{abstract}
Streszczenie
Założona w XVII w. przez Piotra Mohyłę Kijowska Akademia Duchowna dała początek akademickiej teologii w Rosji i dzisiejszej Ukrainie. Zasługą Mohyły jest napisanie Katechizmu, uporządkowanie liturgii, odrodzenie Cerkwi prawosławnej w Rzeczypospolitej.

Artykuł interpretuje krytykę adresowaną pod adresem tradycji mohylańskiej przez rosyjskich, greckich i in. teologów XX wieku (Gieorgij Fłorowskij, Christos Jannaras) i jej obronę (John Meyendorf, Walentin Asmus, Władimir Łosskij, Kallistos Ware, Markus Plested) w świetle współczesnych poszukiwań rosyjskiej i ukraińskiej teologii uniwersyteckiej.
\end{abstract}

\section{Summary}

The name of Peter Mogila is connected with the present Kiev Theological Academy. In the 17th century he created the first orthodox educational institution, for that time in the Polish-Lithuanian Commonwealth. His Academy became a source of science which set the standard of academic theology on the territory of present Ukraine and Russia. Especially important are his merits in creation of catechism, in liturgical reform and state legalization of Orthodox Church in the Polish-Lithuanian Commonwealth.

Some theologians criticize his contribution to theology, protecting uniqueness of Eastern Christianity. This are George Florovsky (in Russian theology) and Christos Yannaras (in Greek theology). However some other thinkers (Meyendorff, Asmus, Lossky, Ware, Plested) are rather inclined to protect the position of Mogila in his aspiration to find synthesis of the 
Eastern and Western Christianity. It is especially clear in the "Byzantine Thomism" popularizing "Latin logic" (medieval scholasticism) in Byzantium.

Nowadays orthodox theology in Ukraine and Russia looks for the place among university humanitarian disciplines, and therefore needs systematization and codification. Therefore methodology of Peter Mogila is urgent again, and we can expect "Mogila revival".

Słow a klucze: Piotr Mohyła, Wschód i Zachód, scholastyka Key words: Peter Mogila, East and West, scholastics

Тема данной статьи напрямую не связана с геополитикой и геокультурой. В отличие от привычного подхода, когда эти термины применяются для осмысления современных международных процессов, она ориентируется на исторический аспект геокультуры и отталкивается от рассмотрения ситуации в Украине в 17-м веке. Далее я перебрасываю мост на ситуацию в 20-м веке, а потому это отнюдь не только историческая статья.

В этом году Киевская Духовная Академия, в которой я преподаю, празднует 400-летие со дня основания Киевской братской школы, которая позже стала коллегией, а потом переросла в Киево-Могилянскую Академию. Это первое высшее учебное заведение в восточной Европе, в котором богословие изучалось в православном ключе. Основание коллегии стало толчком для размышлений о месте митрополита Петра Могилы в традиции «киевского христианства».

Уже простой вопрос отношения к личности Петра Могилы разделяет традиционную российскую и украинскую историографию. Если для российской стороны он скорее причина латинизации исконного православного народа, то для украинской стороны он - канонизированный святой (канонизирован Синодом Украинской Православной Церкви в 1996 году). И потому неудивительно, что в рамках моих размышлений я увидел различные аспекты, которые так или иначе касаются проблем религиозной геополитики или же геокультуры.

Кроме того, эта тема напрямую связана и с польской тематикой. Ведь на то время - в начале 17-го века значительная часть нынешней Украины была частью Речи Посполитой. Лишь через сорок лет после основания коллегии в 1615 году и уже после смерти Могилы произошла знаменательная Переяславская Рада 1654 года, когда украинские земли перешли к Московскому царству.

В то время украинские земли были частью Польского государства, что означает для нас причастность западно-европейской цивилизации. И потому вопрос значения Петра Могилы становится вопросом геополитического выбора того времени: является ли Украина частью европейской цивилизации или же имеет какой-то обособленный путь вместе с Россией? Особую актуальность этот вопрос приобретает в контексте последних бурных событий в политической жизни 
Украины. Сегодня их обычно именуют «революцией достоинства», и толчком для них стал вопрос выбора геополитического развития.

Я хотел бы кратко напомнить основные моменты биографии Могилы. Петр Могила (1597-1647) происходил из молдавского боярского рода. В 15-летнем возрасте он вынужден был переселиться на украинские земли Речи Посполитой. Его родители традиционно исповедовали православную веру, а сам Петр учился в православной Львовской братской школе.

Потом он учился в польской Замойской Академии, а также в Голландии и Франции. Там он получил подлинно европейский кругозор, оставшись при этом верным православной вере. С 1625 года он связывает свою жизнь с Киевом, где сначала становится настоятелем Печерской лавры, а позже Киевским митрополитом.

Для меня наиболее интересным является богословский аспект его деятельности. Получив образование на латыни и, главным образом, по иезуитским образцам, он переносит стандарты тогдашнего европейского образования на киевские земли. Основанная им богословская школа становится рассадником учености для прилегающих православных стран, а со временем распространяется и в пределах Северной Руси.

Такое распространение богословской учености является показательным феноменом. Сегодня, когда стиль тогдашнего образования принято клеймить как «схоластический», важно отметить, что в то время ему не оказалось достойной альтернативы. По моему глубокому убеждению, «схоластика» того времени была необходимым фактором становления богословской науки и без нее позже не возникло бы той среды, в которой бы выросла критика схоластики.

Такая своеобразная диалектика между становлением схоластики и ее критикой привела к становлению академического богословия, которое смогло занять достойное место среди других университетских наук. Этот аспект особенно важен для понимания места богословия в Украине, ведь у нас и сегодня богословие зачастую рассматривается как группа прикладных предметов для подготовки священнослужителей.

Петр Могила изменил формат тогдашнего богословия и вошел в историю благодаря нескольким принципиальным моментам. Во-первых, он подготовил Исповедание Петра Могиль (катехизис, который обсуждался на Киевском соборе в 1640-м году и был принят с некоторыми поправками на соборе в Яссах в 1643-м году). Кроме того, с его именем связывают литургические реформы и издание Требника, в котором многое подверглось правке, анализу, дополнению, и главное - систематизации.

Не менее важным с сегодняшней перспективы является и его близость к государственным властям своего времени - в частности к польскому королю Владиславу IV (1633-1648). Петр Могила активно способствовал избранию его на 
престол, благодаря чему впоследствии стала возможна легализация положения православных в Речи Посполитой.

Возможно, все эти аспекты покажутся здесь не такими уж важными и заслуживающими внимания. Однако для нас в Украине это три важные вещи: формулировка исповедания веры, литургическая реформа и легализация положения православных в, преимущественно, католическом государстве. Их важность и актуальность становятся очевидными, если взглянуть на ситуацию с более поздней перспективы.

Именно на такой более поздней перспективе я и хотел бы сосредоточиться далее. И здесь невозможно не упомянуть Георгия Флоровского с его фундаментальным трудом «Пути русского богословия». В частности, он говорит о «встрече и столкновении двух религиозно-психологических и религиозно-культурных установок и ориентаций - западнической и эллинославянской» ${ }^{1}$.

В терминологии, которую сам Флоровский не использует, можно говорить o «западнической» ориентации как о направленной на рациональное осмысление религиозного опыта. Сам Флоровский симпатизирует скорее «эллинославянской» ориентации, однако если абстрагироваться от симпатий, то можно предположить, что для нее более характерны подсознательные и иррациональные установки и непричастность к тому, что традиционно именуется достижениями эпохи Просвещения.

Богословие как наука, призванная к рефлексии, плохо вписывалась в реалии России. Об этом опять-таки пишет Флоровский: «Богословская наука была принесена в Россию с Запада. Слишком долго она и оставалась в России чужестранкой...»².

Такое противопоставление двух установок и признание, что одна из них явно чуждая - это не только российский опыт. Думаю, здесь полезно будет вспомнить и греческую перспективу, выраженную Христосом Яннарасом в его книге «Православие и Запад» ${ }^{3}$. Мало того, что эта книга противопоставляет «свое и родное» чуждому Западу. Она еще и написана в подражание книге Флоровского - как попытка охватить и осмыслить историю православия в Греции в его противопоставлении западным влияниям.

Две такие значимые книги в российском и греческом контекстах по своей сути противопоставляются замыслу Петра Могилы. Ведь он стремился к обогащению украинской православной культуры со стороны более высокой и привлекательной западной польской культуры и к некоему синтезу восточной и за-

${ }^{1}$ Г. Флоровский, прот. Пути русского богословия, Paris 1983, с. 45.

2 Там же, с. 503.

${ }^{3}$ См. Ch. Yannaras, Orthodoxy and the West: Hellenic Self-Identity in the Modern Age, Massachusetts 2007. Изначально книга была опубликована в 1972 году на греческом и к нынешнему времени выдержала не менее пяти изданий. 
падной традиций. И поэтому здесь стоит привести несколько мнений, которые положительно оценивают вклад Могилы.

Прежде всего, это мнение Пола Мейендорфа о значении Исповедания православной веры Могилы: «Реформа была необходима в ответ на существующую потребность: Петр удовлетворил эту потребность, составив ясную и хорошо структурированную работу» ${ }^{4}$.

В таком же ключе он описывает вклад Петра Могилы в область литургики: «Петр добавил [в свой Требник] сорок абсолютно новых чинов; он переписал, соединил и расширил многие другие ... Его целью были завершенность, ясность цели и чистота, чтобы исключить любую возможность злоупотреблений» ${ }^{5}$. Такой аргумент напоминает призыв в послании апостола Петра «дать ответ с кротостью и благоговением» тем, кто ожидает от нас ответа о наших вере и надежде (1. Пет. 3:15-16).

С принципиально другой стороны защищает Могилу протоиерей Валентин Асмус: «Упреки Могиле сводятся к тому, что вместо византийской школьной традиции он воспринял западную, латинскую ... [Но] никакой византийской традиции давно больше не существовало. Известные наши антизападники - преп. Максим Грек и братья Лихуды - были выпускниками западных университетов» ${ }^{6}$.

И это важный аргумент, ведь ко времени деятельности Петра Могилы Византия уже давно пала, и за прошедшие полтора столетия в значительной степени утратились навыки академического богословия. Идентичность греков к тому времени характеризовалась скорее иррациональными началами и была малопривлекательной для перенятия.

Эту мысль подчеркивает Хауптманн, говоря о «стереотипах и предубеждениях» как альтернативе четко выраженной позиции. Он пишет: «В случае, когда никакое исповедание веры не принимается как образ/форма священного предания, получают распространение другие традиции, ... не имеющие основания в Священном Писании, ...вплоть до широко распространенных стереотипов и предубеждений». ${ }^{7}$

Идея освещения предания светом разума и рефлексии над ним известна и в изложении Владимира Лосского. В своей статье Предание и предания он писал: «Предание действует критически, обнаруживая прежде всего свой не-

${ }^{4}$ J. Meyendorff, The liturgical reforms of Peter Moghila: a new look, St. Vladimir's theological quarterly, V. 29, \#2, 1985, p. 113.

5 Там же, p. 111.

${ }^{6}$ В. Асмус, прот., Святоотеческое наследие и современная иерковная жизнь, [в:] Православное богословие на пороге третьего тысячелетия. Материаль, Москва 2000, с. 70.

7 P. Hauptmann, Das Bekenntnis als Gestalt heiliger Tradition und als Antwort des Glaubens, [в:] Die Heilige Schrift, die Tradition und das Bekenntnis. Erster Bilateraler Theologischer Dialog zwischen der Rumänischen Orthodoxen Kirche und der Evangelischen Kirche in Deutschland vom 19. Bis 23. November $1979 \mathrm{im}$ Haus Hessenkopf in Goslar. Verlag Otto Lembeck, 1982, s. 57. 
гативный и исключающий аспект: оно отвращается «негодных и бабьих басен“ (1 Тим. 4:7), благоговейно принимаемых теми, чей «традиционализм“ состоит в принятии с неограниченным доверием всего, что втирается в жизнь Церкви и остается в ней в силу привычки». ${ }^{8}$

Четыре приведенных мнения - Мейендорфа, Асмуса, Хауптманна и Лосского - представляют, по моему убеждению, значимую альтернативу тенденции изоляционизма и поиска «особого пути», которые близки критикам Петра Могилы.

Другим важным аспектом в осмыслении места киевского святителя является попытка выхода на мета-уровень. Сам Петр Могила пытался ввести позитивные начала в восточно-христианскую традицию того времени благодаря внешним заимствованиям для построения богословской науки. Его противники говорят об извечном «противостоянии Востока и Запада» и необходимости их раздельного существования. Именно поэтому мне представляется интересным привести два мнения, которые работают на релятивизацию границ между христианскими Востоком и Западом.

Первая из них принадлежит Каллисту Уэру, нынешнему митрополиту Вселенского патриархата в Великобритании. В одной из своих ранних статей он исследует взаимоотношение между «схоластикой и православием» ${ }^{9}$. Примечательно, что изначальным импульсом для этой статьи было как раз ответить на радикальное мнение уже упоминавшегося Христоса Яннараса.

В частности он призывает при сравнении Востока и Запада «не противопоставлять лучшее с одной стороны и более худшие образцы с другой стороны» ${ }^{10}$. Что еще важнее, он разрушает кажущееся единство в каждой из сторон противостояния. В истории западного богословия он отмечает «схоластическое богословие» как определенный его этап. Оно развивается в средневековых университетах, придя на смену «монашескому богословию».

Точно так же и на Востоке: помимо ревностных оппонентов схоластики он приводит из среды византийцев и вполне примирительные позиции, что позволяет ему говорить о «византийском томизме». Уэр пишет: «Их впечатлял его [т.е. Фомы Аквината] богословский метод - его систематическая организация материала, его точные определения и различения, обоснованность его аргументации; одним словом, его „латинская логика”. Это должно помочь нам избежать враждебного заключения о том, что византийцы были исключительно „апофатичны” ${ }^{11}$.

${ }^{8}$ В. Лосский, Предание и предания, [в:] Он же, Богословие и боговидение. Сборник статей, под ред. В.Пислякова. Москва 2000, с. 531.

${ }^{9}$ K. Ware, Scholasticism and Orthodoxy: theological method as a factor in the schism, in: Eastern Church Review, Vol. V, Oxford 1973, p. 16-27.

10 Там же, p. 17.

11 Там же, р. 25. 
В этом же русле написана книга Православные прочтения Аквината Маркуса Плестеда ${ }^{12}$. Книга задумана именно как разрушение стереотипа непримиримого противоречия между христианским Востоком и Западом. В ней автор, с одной стороны, пишет о связи Аквината с традицией греческих отцов, а с другой стороны - акцентирует внимание на схоластическом наследии в богословской методологии Паламы, почитаемого многими столпом православия. Плестед делает вывод: «... Палама не настолько „восточный”, а Аквинат не настолько „западный”, как это обычно предполагалось раньше. У каждого есть существенный интерес к традиции другой стороны» ${ }^{13}$.

Обе приведенные работы - Уэра и Плестеда - стоят в группе подобных мнений, которые работают на определенный синтез западного и восточного подходов в богословии, и таким образом, продолжают традицию, заложенную в $17-\mathrm{M}$ веке Петром Могилой. О том, что такая позиция востребована в сегодняшней Украине, свидетельствуют многие факты.

Кроме того, на сегодня «символические книги» становятся снова востребованными для объяснения позиции Православной Церкви в современном мире. Время Петра Могилы порой называется «эпохой конфессионализма», когда confessio, т.е. исповедания веры были важным фактор идентификации различных христианских сообществ. Порой эта эпоха связывается с выветриванием «церковного опыта» и с излишней рационализацией богословия ${ }^{14}$.

Тем не менее, налицо актуальность трудов «символического» характера. Это в первую очередь документы, разрабатываемые в Русской Православной Церкви. С 2000 года эта Церковь приняла несколько документов общецерковного значения, которые фиксируют ее понимание разных аспектов жизни. Это Основы сочииальной концепџии РПЦ (2000), Основные принципь отномения РПЦ к инославию (2000), Основы учения РПЦ о достоинстве, свободе и правах человека (2008).

Подобная кодификация происходит и на общеправославном уровне. Так, на Святой и Великий собор, который призван говорить от имени полноты православной Церкви, выносится ряд документов. Это Отношения Православной Церкви с остальным христианским миром, Миссия Православной Церкви в современном мире и ряд других документов.

Литургические реформы - одна из важных тем, обсуждаемых в рамках подготовки Собора. Пока отложен вопрос «календаря», т.е. попытки организовать общее празднование Рождества Христова и зависимых от него «непереходящих»

12 M. Plested, Orthodox readings of Aquinas, Oxford 2012.

13 Там же, p. 60.

14 Это важная идея К.-Х. Фельми, четко противопоставляющего «старое схоластическое богословие» и «более новое богословие, ориентированное на церковный опыт». См. его книгу «Введение в современное православное богословие», Москва 2014. 
праздников. Однако вопросы литургического характера - «Таинство брака и препятствия к нему», «Важность поста и его соблюдение сегодня» уже разработаны на собеседованиях и совещаниях, предшествующих Собору.

Сам факт собора, который, несмотря на все сложности, должен состояться летом 2016 года, напоминает о «соборности» как важной характеристике Православия. Примечательно, что именно термин «соборность» в 20-м веке во многом определял профиль православия, способный обогатить другие христианские конфессии. А Собор в Яссах 1643 года, закрепивший авторитет Исповедания Петра Mогиль, был инструментом рецепции общеправославным соборным мышлением разработок Могилы, которые до этого были «частным богословским мнением».

И последнее, что мне хотелось бы отметить. Я представляю Духовную академию, имеющую свое начало в учебном заведении, основанном Петром Могилой. Критерий научности и академичности - важные аспекты в богословском сознании Церкви. Они противостоят аморфности и тенденции превалирования иррационального, которое порой именуется «харизматизмом без границ».

Именно в подобном нуждается сегодня православная Церковь в Украине. Получается, что во многом мы сегодня находимся на новом витке истории, когда вновь актуальными становятся вопросы, которые были востребованы в эпоху Петра Могилы, но позже сознательно отодвигались на задний план. Произойдет ли такое «могилянское возрождение» - открытый вопрос, но потребность в нем явно ощущается.

\section{Библиография}

Alexe, S., Metropolit Peter Moghila - Brückenbauer zwischen Ost und West, in: Tausend Jahre zwischen Wolga und Rhein. Internationales Symposion zu Millenium der Taufe der Rus, hrsg. A. Rauch, P. Imhof SJ, München, Zürich 1988.

Meyendorff, P., The liturgical reforms of Peter Moghila: a new look, в: St. Vladimir's theological quarterly, V. 29, \#2, 1985.

Plested, M., Orthodox readings of Aquinas. Oxford University Press 2012.

Ware, K., Scholasticism and Orthodoxy: theological method as a factor in the schism, in: Eastern Church Review, Vol. V, Oxford 1973.

Yannaras Ch., Orthodoxy and the West: Hellenic Self-Identity in the Modern Age, Massachusetts 2007.

Асмус В., протоиерей. К оценке богословия святителя Петра Могилы, митрополита Киевского, в: Богословский сборник. Вып. 10. Православный Свято-Тихоновский богословский институт, Москва 2002.

Бернацкий М. М., Катехизис, в: Православная энциклопедия, Москва, т. 32.

Горбач О., Три українські православні катихизми 17-го віку, в: Праці Богословського факультету Українського Католицького Університету ім. св. Климента Папи. Рим, 1990, т. 71. 
Катехизис Петра Могили, упорядкування проф. А. Жуковського, переклад В. Шевчука. Киів 1996.

Лосский В.Н., Предание и предания в: Он же, Богословие и боговидение. Сборник статей, под ред. В. Пислякова. Москва 2000.

Сильвестр (Стойчев), игум. $K$ вопросу о западном влиянии в богословском наследии святителя Петра Могиль, в: «Труди Київської духовної академії» № 17, 2012. c. $103-112$.

Фельми К.-Х., Введение в современное православное богословие, Москва 2014.

Флоровский, Георгий, прот., Пути русского богословия, Paris 1983. 